\title{
A IMAGEM SOBRE O ENSINO DE LÍNGUA INGLESA NA ESCOLA PÚBLICA: UM REPETÍVEL GENÉRICO
}

\author{
Giovani Forgiarini Aiub*
}

\begin{abstract}
RESUMO: A aprendizagem de línguas estrangeiras em escolas da rede pública, em especial a língua inglesa, tem se caracterizado principalmente por sua alta taxa de insucesso. Este trabalho, filiado à Análise do Discurso francesa, busca saber quais são os discursos que circulam sobre a importância de ensinar e de aprender a língua inglesa sob essas condições de produção, e busca saber qual o imaginário que o professor e o aluno da rede pública fazem dessa língua estrangeira. Para tanto, foram questionados professores e alunos do ensino fundamental e médio, séries regulares e EJA, que já tenham passado pela experiência de (tentar) ensinar e (tentar) aprender outra língua. Os resultados apontam para discursos de ordem genérica.
\end{abstract}

PALAVRAS-CHAVE: Imaginário - Língua Inglesa - Análise do Discurso

ABSTRACT: In public schools foreign language learning, especially English, is characterized mainly by a high failure. Joined to French Discourse Analysis, this work aims to know what discourses are circulating about the importance of teaching and learning English in this context. This paper also searches to know what is the teacher and student's imaginary about the importance of this foreign language. In order to do that, teachers of high and elementary school and their students (the ones who have already had the experience of (trying) teaching and (trying) learning this language) were questioned. The outcomes indicate generic discourses.

KEYWORDS: Imaginary - English Language - Discourse Analysis

\section{DEMARCANDO O ESTUDO}

Conjeturar sobre o ensino e a aprendizagem da língua inglesa é, entre outras tantas questões, se perguntar: por que o ensino dessa língua, em escolas da rede pública $^{1}$, se caracteriza pelo insucesso?

Para falar sobre essa questão, é possível imaginar minimamente que, em um grupo de aprendizes, existem aqueles que se identificam com essa língua estrangeira, que se interessam por ela, que a tratam como importante, e também aqueles que a consideram dispensável, irrelevante, insignificante. Para os que a dispensam, é possível fazer algumas interrogações, tais como: por que não querer aprender uma língua que está por aí, em todos os lugares, nas músicas, nas estampas de roupas, uma língua contemporânea? Por que essa resistência com a língua inglesa? Por outro lado, é

\footnotetext{
* Mestrando do Programa de Pós-Graduação em Letras da UFRGS com apoio da CAPES na especialidade de Análises Textuais e Discursivas. E-mail: gioaiub@gmail.com

${ }^{1}$ Dizer que há insucesso apenas em escolas da rede pública é fechar os olhos para o outro lado do problema. $\mathrm{O}$ insucesso também é característico em escolas da rede privada e em cursos de língua. No entanto, antecipo que este trabalho se centrará no ensino das escolas públicas, uma vez que toma como base de análise os discursos produzidos por sujeitos inscritos dentro desta, e não daquela, realidade.
} 
possível supor também que uma possibilidade para justificar esse não desejo de aprender essa outra língua no âmbito escolar pode girar em torno do imaginário de que essa língua estranha jamais será usada fora da escola, ou melhor, jamais fará parte da realidade daqueles que a consideram dispensável. Assim, ao se tomar como legítima essa desidentificação com a língua inglesa, é aceitável chegar à conclusão (ilusória) de que um insucesso no seu ensino e na sua aprendizagem estaria concretizado.

Em contrapartida, há aqueles aprendizes que não resistem, que se identificam com a língua, que querem aprender a falar a língua inglesa, que a consideram importante, enfim, que a desejam. Neste ponto, poderia ser inquestionável o fato de que esses estudantes, ao se identificarem com a língua inglesa, teriam mais facilidade para aprendê-la, e que esta facilidade realmente os faria aprender. Entretanto, não é bem isso o que acontece. Desse modo, é razoável perguntar: por que esse outro grupo não aprende? Ou melhor, por que não desenvolvem (muito) mais do que aqueles que resistem à língua inglesa, que a tratam como dispensável? É nesse sentido que Revuz (1998, p. 216) diz que "afirmar que o desejo de aprender é o verdadeiro motor da aprendizagem é forçar uma porta aberta. Muito frequentemente, contudo, chega-se a essa porta, mas ela não é transposta". Mas como fazer para transpô-la?

No escopo deste trabalho, tentarei indicar de que forma seria possível dar uma espiada além desta porta. Para tanto, este estudo visa a refletir sobre a forma como a língua inglesa vem sendo discursivizada no contexto da escola pública, uma vez que, nas palavras de Revuz (1998, p. 213), “a aprendizagem de línguas 'estrangeiras' se destaca principalmente pela sua taxa de insucesso". Nesse sentido, tomando como base o discurso de professores de língua inglesa da escola pública e dos alunos desses professores (o que dizem/escrevem/imaginam), esse estudo, filiado à Análise do Discurso francesa (AD), pretende apresentar o modo pelo qual estes dizeres apontam para um silogismo de ordem genérica.

\section{DA BASE TEÓRICA EM ANÁLISE DO DISCURSO: ALGUMAS NOÇÕES}

Dizer que um trabalho se filia à $\mathrm{AD}$, é dizer que ele não está apenas preocupado com o produto (texto), e sim com o processo (discurso), mas que usa esse produto como uma materialidade analítica. É dizer que o trabalho não se faz estritamente na língua sistêmica, mas que, através dela, envolve também o sujeito e a historicidade. Entendese, portanto, que o sujeito se faz na e pela linguagem, a qual só faz sentido "porque se inscreve na história" (ORLANDI, 2005a, p. 25).

Aos olhos da $\mathrm{AD}$, o sujeito é ideológico, e não idealista, pois está interpelado ideologicamente. Para Pêcheux e Fuchs (1975, p. 165-166), interpelação é "o assujeitamento do sujeito como sujeito ideológico, de tal modo que cada um seja conduzido, sem se dar conta, e tendo a impressão de estar exercendo sua livre vontade". A partir disso, pode-se dizer que o sujeito é descentrado, é assujeitado, é cindido. Ele não é o dono do seu dizer e "atua sob o efeito de duas ilusões: pensa ser a fonte do seu dizer e ser responsável pelo que diz" (INDURSKY, 2000, p. 70).

Outro conceito relevante para a compreensão desta pesquisa diz respeito ao processo de identificação do sujeito. Pêcheux (1975) diz que para haver identificação (com uma língua estrangeira, por exemplo), é preciso que haja uma tomada de posição. E essa tomada de posição do sujeito ocorre através de modalidades de desdobramento, que podem ser de três tipos. 
A primeira modalidade de desdobramento é aquela em que o sujeito, revestido de uma forma-sujeito, reproduz a evidência ideológica de dada formação discursiva (FD), ou seja, reproduz, sem questionar, os saberes da FD pela qual ele está dominado. A segunda modalidade diz respeito a uma tomada de posição do sujeito que luta contra essa evidência ideológica. Aqui o sujeito "se contra-identifica com a formação discursiva que lhe é imposta" (PÊCHEUX, 1975, p. 215), em outras palavras, mesmo questionando a ideologia vigente, ele ainda ocupa um lugar dentro dessa mesma FD, porém, em outra posição-sujeito. Com efeito, essa segunda modalidade de desdobramento, a contraidentificação, é a que dá espaço para que haja uma FD heterogênea, uma vez que é possível se questionar a evidência ideológica a partir de distintas posições, ou seja, trazendo saberes de outras FDs, do interdiscurso. A terceira modalidade diz respeito ao processo de desidentificação com os saberes de dada FD. Neste caso, a contraidentificação é tão forte que não há mais espaço para que o sujeito ainda ocupe lugar na mesma FD. Ele, diferente do que se possa imaginar, não fica livre, solto, mas recai sobre outra FD.

Nesse sentido, cabe pensar na tomada de posição como uma tomada da palavra, pois "quando se toma a palavra, sabemos, toma-se um lugar que dirá respeito às relações de poder, mas, simultaneamente, 'toma-se' a língua, que tem um real específico, uma ordem própria" (SERRANI-INFANTE, 1998a, p. 248). Assim, ao tomar a palavra, o sujeito é tomado pela língua, ele é capturado.

Nessa perspectiva, é possível dizer que o sujeito precisa inscrever-se em novas formas de dizer para que produza sentido(s) em língua estrangeira, ou seja, o sujeito precisa ser tomado pela palavra, uma vez que

\footnotetext{
precisa inscrever-se em processos identificatórios nessa língua e, portanto, acaba por realizar movimentos que coloquem em jogo um outro imaginário, já que a produção de sentidos não ocorre no vazio. Esse imaginário [...] tem uma função de sustentação da identificação para a formação da identidade, e só por um trabalho de desarranjo/rearranjo da forma-sujeito [...] essa identidade pode estar sempre em formação/transformação, possibilitando ao sujeito o encontro com outros lugares de dizer. (NARDI, 2005, p. 162)
}

Desse modo, o sujeito, para produzir sentido nessa outra língua, precisa realizar movimentos que desestabilizem o seu imaginário, fazendo com que se instaure outro. Sendo assim, é preciso ser/estar suscetível a uma transformação, a um desarranjo/rearranjo para a formação de sua identidade, que, diga-se de passagem, não é imutável. Para trabalhar com esse jogo de posicionamentos do sujeito do/no discurso, é relevante tratar de representações no processo discursivo, as quais têm relação com as condições de produção do discurso, pois "o que funciona nos processos discursivos é uma série de formações imaginárias que designam o lugar que A e B se atribuem cada um a $s i$ e ao outro, a imagem que eles fazem de seu próprio lugar e do lugar do outro" (PÊCHEUX, 1969, p. 82). Nesse sentido, a imagem que cada sujeito atribui para si e para o outro, ou melhor, a imagem que o sujeito tem de seu lugar, do lugar do outro, a imagem que o sujeito faz da imagem que o outro lhe tem, e assim sucessivamente, é um processo que ocorre no âmbito dessas formações (as imaginárias). Além, ainda, da imagem que ambos (o sujeito e seu interlocutor) fazem do referente, o objeto imaginário. Ademais, cabe dizer que as formações imaginárias são sempre originadas de processos discursivos anteriores, ou seja, são atravessadas por todo um já-dito e um já-ouvido (ibid., p. 85). 
Dessa forma, é possível dizer que a língua(gem) é perpassada pelo imaginário, representado pela formação imaginária e também pela ideologia, a partir das formações ideológicas. Portanto, é importante dizer que a ideologia trabalha no discurso, pois, de acordo com Pêcheux (1975, p. 160),

\begin{abstract}
o sentido de uma palavra, de uma expressão, de uma proposição, etc., não existe em si mesmo (isto é, em sua relação transparente com a literalidade do significante), mas, ao contrário, é determinado pelas posições ideológicas que estão em jogo no processo sócio-histórico no qual as palavras, expressões e proposições são produzidas (isto é, reproduzidas).
\end{abstract}

A partir do exposto, é possível dizer que uma palavra muda de sentido de acordo com a posição na qual o sujeito enunciador se coloca ao empregá-la, sendo assim, dizer que há um sentido literal é escamotear a ideologia que interpela todo sujeito.

Desse modo, é também coerente afirmar que a ideologia é materializada no discurso, sendo através dele que se concebe/conhece aquela. Orlandi (2006, p. 17) diz que "não podemos pensar o sentido e o sujeito sem pensar a ideologia. Do mesmo modo que não podemos pensar a ideologia, em termos discursivos, sem pensar a linguagem".

Depois dessa breve passagem pelos conceitos que dão sustentação a este trabalho, passo a apresentar o que imaginam os professores sobre a importância de ensinar (e também aprender) a língua inglesa na escola pública. Dou início aqui a uma possível interpretação de seus dizeres.

\title{
A IMAGEM DO SUJEITO-PROFESSOR: UM REPETÍVEL GENÉRICO
}

A composição do objeto analisável contou com a colaboração de seis professores de língua inglesa de escolas da rede pública, dois de escolas municipais e quatro de estaduais, sendo que todos eles lecionavam na região metropolitana de Porto Alegre/RS para alunos do ensino fundamental, séries finais, ou ensino médio. Cada professor respondeu às seguintes perguntas em forma de questionário²: (a) Qual a importância de ensinar a língua inglesa na escola pública?; (b) Na sua opinião, seus alunos acham a língua inglesa importante? Por quê?; e (c) Por que você acha que a sua opinião, sobre a importância de língua inglesa, se assemelha/se diferencia da de seus alunos?

Com estas questões, tentei focar a imagem que esses sujeitos-professores fazem da imagem que os outros sujeitos (representados na figura dos alunos) têm do mesmo referente, formando, assim, não o discurso em si, mas a materialidade, um construído que se possa analisar. E é desse todo já construído que se dá a análise, fazendo os recortes discursivos, pois "o recorte é uma unidade discursiva. Por unidade discursiva entendemos fragmentos correlacionados de linguagem-e-situação. Assim, um recorte é um fragmento de situação discursiva" (ORLANDI, 1984, p. 14). E, ainda com Orlandi (2005a, p. 62), "não há discurso fechado em si, mas um processo discursivo do qual se podem recortar e analisar estados diferentes". Portanto, a situação discursiva, neste caso, foi estabelecida, assim, não pelo questionamento que foi conferido ao sujeitoprofessor e ao sujeito-aprendiz - o que houve aqui foi apenas uma transposição do já-lá. E é a partir deste já-lá, materializado no texto, o produto, que se constituirá a análise do discurso destes sujeitos envolvidos no processo de ensino e aprendizagem da língua estrangeira.

\footnotetext{
${ }^{2}$ Os questionários foram respondidos entre o segundo semestre de 2006 e o primeiro semestre de 2007.
} 
Para trabalhar com a análise do discurso dos professores, vou me valer dos estudos de Tfouni (1995) e Tfouni e Tfouni (2007) a respeito dos genéricos, a fim de enriquecer a teoria da AD apresentada anteriormente. Segundo esses autores, o genérico "funciona como um mandamento que faz o sujeito gozar", ao ocupar uma posição ideologicamente definida" (TFOUNI; TFOUNI, 2007, p. 293). Nesse sentido, os genéricos, como concebe Tfouni (1995), podem ser de duas ordens: os presentes nas premissas dos silogismos e os que ocorrem nas narrativas. Aqui, tomarei como base os de primeiro tipo, os do silogismo.

Os genéricos dos silogismos são aqueles que tentam camuflar as marcas da enunciação, dando a impressão de que não há outros sentidos a não ser aquele aparente. Em outras palavras, "o genérico do silogismo tenta apagar o 'interdiscurso', instituindo a ilusão de que só o que é efetivamente 'dito' faz sentido (o intradiscurso)" (TFOUNI, 1995 , p. 80). Neste ponto, vale lembrar que o interdiscurso se refere ao "todo o complexo com dominante das formações discursivas", ao "pré-construído", ao "semprejá-aí", enquanto que o intradiscurso "é o funcionamento do discurso com relação a si mesmo", ou seja, a relação do que é dito agora com o que foi dito antes e o que será dito depois (PÊCHEUX, 1975, p. 166).

Embora os genéricos de silogismo tentem apagar as marcas da enunciação, procurarei buscar possíveis interpretações a partir das paráfrases produzidas pelos professores de língua inglesa da escola pública com base em um genérico. Desse modo, cabe aqui dizer que

os processos parafrásticos são aqueles pelos quais em todo o dizer há sempre algo que se mantém, isto é, o dizível, a memória. A paráfrase apresenta, assim, o retorno aos mesmos espaços de dizer. Produzem-se diferentes formulações do mesmo dizer sedimentado. (ORLANDI, 2005a, p. 36)

Em virtude de os dizeres dos professores estarem, quase que na sua totalidade, relacionando a importância do saber inglês ao mercado de trabalho, o genérico que proponho, então, aparece na ordem de um silogismo.

Inglês é solicitado no mercado de trabalho. Os alunos sabem inglês. Logo, os alunos entrarão no mercado de trabalho.

A partir desse genérico em forma de silogismo é que pretendo definir uma formação discursiva na qual este saber seja dominante. Chamarei essa formação discursiva de FD do Repetível Genérico, na qual a importância de se aprender a língua inglesa está atrelada à conquista de um emprego. Vale ressaltar ainda que, dentro desta FD, há um saber maior: ensinar/aprender língua inglesa na escola pública é importante.

Será analisado, então, como se dá a relação do sujeito do discurso com essa FD para verificar como trabalha o discurso nessas condições de produção. Ao recortarmos o discurso de um professor do ensino fundamental regular $[\mathrm{P} 1]^{4}$, aparecem as primeiras sequências discursivas:

As pessoas que têm conhecimento, mesmo que básico de inglês, possuem mais chances de competir no mercado de trabalho. [P1]

\footnotetext{
${ }^{3}$ Aqui reproduzo a nota dos autores que acompanha a citação: “O termo 'gozar' vem da Psicanálise, e será usado aqui para comentar aspectos subjetivos do assujeitamento ideológico, ou as formas pelas quais o gozo pode funcionar como força que captura o sujeito" (TFOUNI; TFOUNI, 2007, p. 293).

${ }^{4}$ Usarei P1, P2, etc., para designar diferentes professores.
} 
Uma minoria vê importância no aprendizado de Língua inglesa. Esses são aqueles que têm uma perspectiva de futuro, de bons empregos. A maioria dos meus alunos diz que aprender inglês não serve pra nada. Há a famosa sentença: "Para que aprender inglês se não sei nem Português direito?”, a qual escuto várias vezes. [P1]

É possível perceber nessas sequências discursivas que o professor demonstra certa preocupação com o futuro dos alunos. Entretanto, este futuro é um futuro que vem na ordem da competição no mercado de trabalho, identificando-se, desse modo, com a FD do Repetível Genérico.

Assim, pode-se dizer que o que está em jogo aqui é a ilusão de que sem a língua inglesa as chances de um bom emprego se esgotam. Vale lembrar aqui que a concepção de o que é um bom emprego demonstra um posicionamento ideológico do professor, segundo o qual empregos em que o inglês não é exigido não são bons. O que é, afinal, um bom emprego? Será aquele consagrado e de prestígio? Ser professor de língua inglesa é ter um bom emprego, uma vez que para ser professor deste componente curricular é necessário que se saiba esse idioma? Será que, dentro da realidade desses alunos, a partir de suas vivências, eles conseguem vislumbrar um bom emprego na mesma concepção que o professor lhe atribui? Dentro de suas realidades, quem se vale do saber inglês para conquistar um lugar no mercado de trabalho?

Uma provável resposta a essas últimas perguntas está no próprio dizer daquele professor, uma vez que, para ele, a maior parte de seus alunos diz que aprender inglês não serve para nada. Assim, se inglês não serve para nada, na imagem que o professor faz da imagem que seus alunos fazem do mesmo referente, é possível concluir que seus alunos não veem importância em aprender a língua inglesa no mesmo viés dado pelo professor, que é aprender esse idioma para competir no mercado de trabalho.

$\mathrm{O}$ que caberia aqui para que fosse dada a devida relevância à aprendizagem de língua inglesa é uma transformação/modificação no enfoque dado ao ensino, isto é, uma transformação/modificação no viés que privilegia o saber inglês relacionado à conquista de um bom emprego. O que caberia, em outras palavras, é uma desestabilização da posição-sujeito ocupada por este professor dentro da FD do Repetível Genérico. Digo uma desestabilização, porque uma desidentificação com esta FD poderia vir no sentido de que ensinar inglês não seja importante. Poderia haver, então, uma desidentificação com o saber maior da FD: o de que aprender inglês é importante (mesmo que seja para o mercado de trabalho).

Por que, entretanto, neste viés de ensino, a aprendizagem, como disse o professor, não é vista pelos alunos (à sua imagem, vale salientar) como algo importante? Talvez a resposta seja mais simples do que se possa imaginar. Geralmente, alunos do ensino fundamental ainda não estão tão preocupados com o mercado de trabalho, em conseguir empregos, mais que isso, bons empregos, visto que esses alunos ainda têm uma base de sustentação financeira, mesmo que muitas vezes precária, na família, além de outras implicações legais previstas pelo Estatuto da Criança e do Adolescente, como a entrada no mercado de trabalho a partir dos 16 anos de idade. Conquistar um bom emprego, nesse sentido, não faz parte ainda da realidade desses alunos. Mas, e se fizesse parte, como no caso de alunos da Educação de Jovens e Adultos (EJA), onde há uma maioria considerável de trabalhadores, aprender inglês seria importante? Deixarei esta questão em aberto para trabalhar com ela nas análises dos discursos dos alunos desta realidade. 
A partir de agora, apresento os dizeres de um professor do ensino fundamental regular, dizeres que foram recortados da seguinte maneira:

A grande maioria dos meus alunos vê importância no inglês, porque o inglês é, segundo eles, cada vez mais importante para conseguir um bom emprego atualmente. $[\mathrm{P} 2]$

Nesse recorte discursivo, o professor projeta o seu discurso a partir da imagem que ele faz do dizer de seus alunos, tentando não se ausentar de dizer o porquê da importância de se saber inglês, mas passando a sua posição ideológica para o dizer do outro, nesse caso, os alunos. Há ainda a possibilidade de os dizeres dos alunos serem uma reprodução do discurso do professor, mas deixarei essa questão para ser examinada na próxima seção.

Voltando a esse recorte, a opinião desse professor, assim como a de P1, reflete o genérico apresentado. Portanto, o sujeito assume uma posição-sujeito que reproduz o saber dominante da FD do Repetível Genérico. Pode-se perceber mais claramente isso em um segundo recorte desse mesmo sujeito e também em um recorte do discurso de P3.

As opiniões, minha e dos meus alunos, sobre a importância do inglês são semelhantes porque o inglês é realmente muito importante para que se consiga um bom emprego hoje em dia. [P2]

Cada vez mais eu vejo brotar nos alunos o interesse por aprender inglês, seja para conseguir um bom emprego ou adquirir um conhecimento em outra cultura. [P3]

Fica clara, portanto, a reprodução da evidência ideológica da FD. Mas, diferente do que ocorre com P1, esses professores ( $\mathrm{P} 2$ e P3, ambos do ensino fundamental regular) creem que a ideologia, que os domina, domina também o outro, fechando-se para outros saberes. Saber inglês, aqui, só tem uma utilidade: conseguir o que eles imaginam que seja um bom emprego. Nesse sentido, relembro Orlandi (2005b, p. 104), que diz: "quanto mais centrado o sujeito, mais cegamente ele está preso a sua ilusão de autonomia ideologicamente constituída". Esse é um bom exemplo de como a ideologia trabalha no discurso. Na mesma ordem desses dizeres, surge o deste professor da EJA, que segue:

A principal importância de ensinar Língua Inglesa na escola pública é que este idioma é muito necessário para a sociedade nos dias de hoje; pois, além de ser solicitado em grande parte dos empregos, é também um acréscimo de cultura aos indivíduos. [P4]

Chamo a atenção, no entanto, para outras menções que surgem no discurso de P3 e que também se repetem no de P4 (professor da EJA), sobre adquirir conhecimento em outra cultura (P3) e acréscimo de cultura aos individuos (P4). Aqui se percebe, além de uma paráfrase do genérico atrelado à FD em questão (P3: conseguir um bom emprego; e P4: solicitado em grande parte dos empregos), outro saber que tenta se instaurar dentro da mesma FD. Apesar disso, esse saber não se sustenta, pois é possível adquirir e ter acréscimo de cultura mesmo em língua materna. Seria esta uma razão para aprender língua inglesa: adquirir outras culturas? De quais culturas se fala aqui? Será que é uma cultura estereotipada, reduzida a hábitos genéricos de um povo? Ao não desenvolverem tais argumentos, os professores (P3 e P4) calam diante do que eles mesmos apresentam. Aqui há o que se pode chamar de uma política de silêncio, que, para Orlandi (2007, p. 73-74), é onde "se apagam os sentidos que se quer evitar, sentidos que poderiam instalar o trabalho significativo de uma 'outra' formação discursiva, uma 'outra' região de 
sentidos". Nesses casos, essa outra região de sentidos não se desenvolve, não dá abertura para que o sujeito assuma outra posição-sujeito.

O que está em questão neste trabalho é saber o que vem sendo discursivizado sobre a importância da língua inglesa em escolas públicas para, a partir disso, propor uma tomada de posição (tomada da palavra em língua estrangeira) por parte do aprendiz. Pelo que se viu até agora, os discursos desses professores não instigam o aluno a essa tomada. Trabalham com uma ideologia marcada por um genérico que, dentro desta realidade (não imaginária), não se sustenta, pois a conquista de um espaço no mercado de trabalho não está (somente) atrelada ao saber inglês.

Como acontece com o de $\mathrm{P} 1$, o próximo recorte discursivo (o de $\mathrm{P} 5$, professor do Ensino Fundamental), exclui o outro (o aprendiz) do saber maior da FD: o de que inglês é importante. Segue o recorte:

Na minha opinião, a maioria dos meus alunos não acha importante a Lingua Inglesa porque eles não conseguem ver uma utilidade real e imediata para o seu uso. [P5]

Ao fazer essa exclusão do outro, dizendo que os alunos não acham inglês importante porque não há uma utilidade em saber tal língua, esse professor vai até um ponto que poderia ser interessante para que uma possível tomada da palavra ocorra. Porém, ele vai até essa porta (que está aberta), mas não transpassa (cf. REVUZ, 1998). Ao fazer tal movimentação, esse sujeito se coloca em outra posição-sujeito dentro da FD do Repetível Genérico, pois, diferentemente do que os outros professores não percebem (ou não querem/podem perceber), ele se dá conta de que há um problema, uma falta de identificação com a língua inglesa, embora não se movimente para tentar solucioná-lo.

O que pretendo dizer com isso é que esse sujeito, conhecedor de que a língua inglesa, no enfoque em que a ela vem sendo dada, não faz sentido para os aprendizes, não procura a tal utilidade real e imediata. O que imagina esse professor que seria uma utilidade real e imediata? Conseguir bons empregos? O que se pode dizer disso é que alunos do Ensino Fundamental regular não vão imediatamente ocupar um lugar no mercado de trabalho, por isso que não se torna importante saber inglês. Caberia, a esse professor, então, tentar buscar o que faz sentido para esses alunos, já que, neste viés de ensino, a aprendizagem de língua inglesa não é importante, não faz sentido, é um nonsense.

Como foi possível perceber até aqui, a posição-sujeito desses professores é fortemente marcada pelo saber da FD do Repetível Genérico. Com exceção de P1 e P5, nos quais a ideologia da FD dominante os marca, mas dá brechas para ver a posição do outro, P2, P3 e P4 estão fortemente dominados por uma FD que faz com que a posição do outro seja apagada.

Ainda sobre esses professores (P2, P3 e P4), é possível dizer que não há uma identificação com as condições de produção de seus alunos. Aqui o sujeito do discurso, representado por P2, P3 e P4, se mostra profundamente identificado com a formasujeito da FD que o afeta, a tal ponto que não há lugar para uma movimentação. Assim, sem essa movimentação, esse desarranjo, a captura do outro fica cada vez mais distante.

Para finalizar essa parte da análise, seguem os dizeres de um professor do Ensino Médio ([P6]) que foram recortados deste modo:

Inglês é importante para tornar o aluno apto a navegar na Internet e entrar em sites ou chats, bem como alguns jogos. [P6] 
A importância de se ensinar Língua Inglesa na escola pública é fazer com que o aluno entre em contato com outro idioma, que não é o seu, e sua respectiva cultura, possibilitando-lhe conhecer o Inglês que ele ouve nas músicas e nos filmes. [P6]

Como é possível notar, esse sujeito do discurso se afasta de uma posição mais central dentro da FD do Repetível Genérico, pois trata do diferente. Não vem na ordem da paráfrase, mas sim da polissemia, do diferente dentro do mesmo. Para Orlandi (2005a, p. 36), "a polissemia é o deslocamento, rupturas no processo de significação" e também "a simultaneidade de movimentos distintos de sentido no mesmo objeto simbólico" (ibid., p. 38). Nesse sentido, pode-se dizer que é diferente, porque não reproduz mais o silogismo genérico da FD, e mesmo porque ainda ensinar/aprender inglês na escola pública é considerado importante. O que ocorre, nesse caso, é uma contraidentificação do sujeito com a FD que o domina (a segunda modalidade de Pêcheux), pois não se desidentifica totalmente com ela. Há ainda um saber maior que faz parte da FD em questão, e esse sujeito não se afasta dele: aprender a língua inglesa é importante, mas nesse caso não mais para a conquista de um emprego. Assim, a posição que esse sujeito ocupa na FD do Repetível Genérico é diferente e mais distante das ocupadas por P1 e P5, e mais distante ainda da ocupada por P2, P3 e P4.

Na posição-sujeito de $\mathrm{P} 6$, assuntos mais palpáveis são levados em conta. Em uma realidade onde a Internet, os jogos eletrônicos e músicas em inglês estão presentes - cabe lembrar, no entanto, que não é em toda realidade, não é em toda escola pública -, um ensino de língua inglesa, nesse viés, pode abrir brechas para uma tomada de posição que abranja a captura dessa outra língua.

Como alertei anteriormente, este sujeito do discurso assume outra posiçãosujeito dentro da FD do Repetível Genérico. O que há aqui é a contraidentificação com o silogismo genérico presente nas outras duas posições-sujeito. Afirmo que é a mesma FD porque, nas duas posições-sujeito anteriores (uma representada por P2, P3 e P4, e outra por P1 e P5) e também na posição-sujeito de P6, há um saber maior em comum: ensinar/aprender inglês na escola pública é importante. Esta última posição, a de P6, assim, toma outro lugar dentro da mesma FD. Para lembrar Pêcheux (1975), a segunda modalidade de desdobramento, a da contraidentificação, dá brechas para se ter, dentro desta mesma FD, três distintas posições-sujeito. A primeira delas mais central, isto é, uma posição-sujeito onde há uma identificação plena, onde não há espaço para visualizar o outro. Esta primeira posição, no caso desta análise, pode ser representada pelo discurso produzido por P2, P3 e P4. Uma segunda posição-sujeito, representada por P1 e P5, é semelhante à primeira. Entretanto, o que não a torna mesma é o fato de haver lugar para que se perceba o outro. Já a terceira posição-sujeito é uma contraidentificação com o genérico, pois o questiona sem deixar de lado um saber que também compõe essa FD. Essa terceira posição-sujeito é representada por P6.

Ao cabo da conclusão desta primeira parte da análise, outra proposição relevante ainda sobre os dizeres dos professores diz respeito à última posição apresentada, pois é a partir dela que creio ser possível uma tomada da palavra pelos alunos, uma captura do aprendiz, abrindo espaço para saberes da ordem de uma realidade mais palpável e não de uma realidade distante dos aprendizes. 


\section{A IMAGEM DO SUJEITO-APRENDIZ: UMA (RE)PRODUÇÃO DE DISCURSOS}

Neste espaço, serão examinados os discursos dos aprendizes. Verificar-se-á como há (e se há) uma filiação à FD do Repetível Genérico, como esses sujeitos se identificam (ou não) com este saber dominante: o de que ter conhecimento em língua inglesa é importante para entrar no mercado de trabalho. Como foi possível perceber, pretendo trabalhar com a mesma FD, pois creio que é dentro dela, mas com uma contraidentificação, que se possa tomar a palavra em língua inglesa.

Do mesmo modo que os professores, diversos alunos desses professores (pertencentes à escola pública) responderam, em forma de questionário, as seguintes perguntas: (a) Qual a importância de aprender língua inglesa na escola?; (b) Na sua opinião, seu professor acha língua inglesa importante? Por quê?; e (c) Por que você acha que a sua opinião, sobre a importância de língua inglesa, se assemelha/se diferencia da de seu professor?

Como primeiro passo, apresento o recorte discursivo de cinco aprendizes ${ }^{5}$ que se identificaram com a FD do Repetível Genérico. A seguir, recortes discursivos destes alunos. ${ }^{6}$

Inglês é importante porque hoje em dia todos os lugares exigem o aprendizado da língua inglesa. (EM) [A1]

A importância é que hoje precisamos muito da Língua Inglesa, e não só dela, mas também de outras, para o mercado de trabalho. (EM) [A2]

Em um mundo americanizado é muito importante aprender a língua que é mais solicitada em empregos. (EM) [A3]

Eu gostaria de aprender a língua inglesa porque quando crescer vai ser preciso talvez para procurar trabalho, e para mais coisas. (EF) [A4]

O inglês é bom para o futuro. (EF) [A5]

A partir desses recortes, é notável uma identificação com a FD do Repetível Genérico, pois eles parafraseiam o silogismo genérico proposto anteriormente. Além disso, cabe ressaltar que, grande parte dos aprendizes que disseram/imaginam que a língua inglesa seja importante para o mercado de trabalho são do Ensino Fundamental e Médio regular. Mas que quero dizer com isso? Há aí uma tendência forte à reprodução do discurso dos professores que, em sua maioria, reproduzem fielmente a ideologia da FD que os domina, e que também abriga uma grande amostragem de aprendizes que estão construindo/transformando as suas visões de mundo. Dessa forma, o que esses alunos reproduzem são dizeres vindos do outro, um outro que os constitui ideologicamente.

Ao resgatar o dizer de A1, tem-se que todos os lugares exigem o aprendizado da língua inglesa. $\mathrm{O}$ que esse aluno do ensino médio pretende significar com todos os lugares? Que todos os lugares são esses? Serão lugares fora da escola? O que há, neste caso, é um jogo no qual todos e língua inglesa se remetem a algo amplo e podem ser atrelados ao mercado de trabalho, à conquista de um espaço onde, em todos, a língua inglesa é exigida. Há aí uma preocupação em conquistar este espaço; por esta razão a

\footnotetext{
${ }^{5}$ Embora tenha sido questionada uma turma de cada um dos professores participantes da pesquisa, tomarei como base aqueles recortes que podem expressar/expressam uma representação do sujeito do/no discurso.

${ }^{6}$ Para fins de explicação, ao lado do recorte, entre parênteses, as siglas EF, EM ou EJA, onde são, respectivamente, alunos do Ensino Fundamental, do Ensino Médio, ou da Educação de Jovens e Adultos; e, entre colchetes, a letra "A" mais um número arábico para identificar diferentes aprendizes.
} 
língua inglesa é considerada importante. O mesmo ocorre com A5, que diz que inglês é bom para o futuro. Volto a questionar: que futuro é este? Em um imaginário no qual o mercado de trabalho ainda não faz parte da realidade desse sujeito, é atrelado o saber inglês a um futuro que, com o inglês, será bom.

É possível perceber que esses alunos não têm convicção de que, ao saber inglês, terão de fato espaço no mercado de trabalho. Afirmo isto a partir do seguinte exemplo, o dizer de A4: Eu gostaria de aprender a língua inglesa porque quando crescer vai ser preciso talvez para procurar trabalho. Este aprendiz do Ensino Fundamental, ao acrescentar o advérbio talvez, expressa uma dúvida em relação à exigência da língua inglesa em seu futuro trabalho. Quando ele crescer, isto é, quando tiver idade adequada para competir no mercado de trabalho, ele acredita, hoje, que inglês será importante, porém, não tem plena convicção. Entretanto, não aponta outros fatores, além desse, que fazem o inglês ser relevante para ele, filiando-se, assim, à FD do Repetível Genérico.

Para uma tomada de posição onde haja um processo de captura dessa língua, não se pode afirmar a esses sujeitos-aprendizes que inglês (só) seja útil para o mercado de trabalho. Fica evidente aqui que esta é uma realidade distante para os alunos do Ensino Fundamental. Entretanto, não vou me aprofundar no mérito de saber se o inglês é realmente importante para o mercado de trabalho. Como se sabe, há muito mais profissões no Brasil que não exigem o idioma inglês àquelas em que inglês é fundamental. Tanto os professores quanto os alunos não mencionam em parte alguma de seus dizeres que profissões são estas. Há aqui uma reprodução de um genérico que tenta apagar outras vozes, e o sujeito, ao enunciar, tem a ilusão de que não há outras interpretações possíveis.

Deste modo, para que aconteça uma tomada de posição que abranja tanto a língua materna quanto a captura desta outra língua, é preciso que ocorra uma modificação na posição-sujeito, uma posição-sujeito que abarque outros saberes. Seguindo nesta linha, outros alunos entram em cena a partir de agora. Serão mostrados recortes discursivos nos quais outros aprendizes apresentam outros saberes, outras preocupações com a aprendizagem da língua inglesa. Seguem os recortes:

É importante para traduzir jogos de vídeo game e alguns serviços pedem cursos de inglês, serve para muitas coisas e a gente pode precisar no futuro. Inglês é legal. As coisas nos computadores são em inglês. Eu gosto de inglês. (EF) [A6]

Lingua inglesa é importante porque a gente precisa para ler algumas coisas na Internet, às vezes até para conseguir emprego é preciso aprender a língua inglesa. (EF) [A7]

Os melhores filmes sua língua é em inglês, por esses e outros motivos, o inglês é muito importante. (EM) [A8]

Hoje em dia, nós (os alunos) precisamos de um inglês descontraído, divertido, e o inglês que a professora passa é muito "nada a ver", coisas que a gente nem acha importante. Eu queria aprender inglês para falar muito bem, porque, quando for mais velho, queria ir para outros lugares, queria saber como se fala. É que na escola, eles ensinam o básico, não ensinam o que é importante. (EF) [A9]

Como é possível notar nos enunciados destes alunos, a importância de aprender a língua inglesa remete para outras áreas, como traduzir jogos de vídeo game e coisas do computador (A6), ler algumas coisas na internet (A7) e filmes em inglês (A8). Aqui é perceptível uma filiação à FD do Repetível Genérico, entretanto, esses sujeitos assumem outra posição-sujeito nesta mesma FD, pois não descartam a importância de aprender a língua inglesa. O que ocorre é que eles deslocam esta importância. Vale 
salientar ainda que não se trata, em A6 e A7, de uma reprodução do dizer do professor, pois esses não são alunos de P6 que, no seu discurso, instaurou esses saberes. Esses são alunos da realidade de P2 e P3 respectivamente. Porém, como se viu, aqueles professores (P2 e P3) estão tão marcados pela ideologia dominante da FD do Repetível Genérico que se fecham para outros saberes que estão em um lugar nada distante: as suas próprias salas de aula.

Nos casos de A6, A7 e A8, o que há é uma contraidentificação com o silogismo genérico presente na $\mathrm{FD}$, porém essa contraidentificação não é tão forte a ponto de deslocar o sujeito para outra FD, sendo que ainda ecoam vozes do silogismo genérico no dizer de A6 (alguns serviços pedem cursos de inglês) e também no de A7 (às vezes até para conseguir emprego é preciso aprender a língua inglesa). Apesar desses ecos, estes sujeitos não se identificam plenamente com a FD do Repetível Genérico, pois enunciam a partir de uma posição-sujeito um pouco diferente, a partir da qual observam outras relevâncias para o ensino/aprendizagem desta língua outra.

Na sequência discursiva de A9, a importância de saber inglês está relacionada ao falar bem, a conhecer outros lugares onde o inglês seja realmente usado. Este sujeito justifica esta posição ao afirmar que na escola o ensino básico de inglês não é importante, o que provavelmente esteja ligado a exercícios gramaticais descontextualizados, desistoricizados. Há aqui um sujeito da falta, que deseja ir para outros lugares. Relacionando essa sua vontade aos modelos de aulas com o qual está acostumado, ele diz que o inglês que a professora passa é muito "nada a ver", pois é um inglês que não captura, que não desestabiliza; complementando, é um inglês que trabalha provavelmente enfocando os conhecimentos gramaticais e a tradução de léxicos totalmente descontextualizados.

Neste ponto, vale ressaltar que o trabalho com os léxicos e com as regras gramaticais de determinada língua são fundamentais para a sua construção e formulação. No entanto, não se pode fazer apenas isto. Para corroborar, os apontamentos de Nardi (2002, p. 131) são essenciais, pois,

se queremos reconhecer os pronomes, advérbios, adjetivos e sua forma de emprego, que o façamos pensando nos efeitos de sentidos que provocam no texto, seu papel nessa unidade de discurso, mas sem fazer disso o objeto central do estudo do texto, sem prender o texto nos limites da gramática.

Assim, para uma busca de efeitos de sentido, não se pode deixar que o professor feche os olhos para os saberes e interesses desses alunos. Para uma captura do outro, é preciso que se instaure um processo de tomada da palavra, isto é, "a inscrição deste sujeito-aprendiz numa rede de discursos com os quais ele vai identificar-se para produzir sentidos para aquilo que diz" (ibid., p. 129).

Como foi possível notar, a posição que esses sujeitos ocupam dentro da FD do Repetível Genérico se refere à contraidentificação, pois se distanciam da forma-sujeito predominante nesta FD, buscando, consequentemente, outros saberes no interdiscurso. Nesta perspectiva, essa posição inicia uma possível busca para um fazer sentido em língua inglesa, a busca da tomada da palavra pelo que lhes é familiar, pelo que lhes faz identificar-se com esta outra língua.

Os próximos recortes discursivos que apresento estão na ordem da desidentificação com o saber maior da FD do Repetível Genérico. Aqui, é demonstrado que a língua inglesa não é importante, ou que, pelo menos até esse momento, não foi 
apresentada uma utilidade real e imediata (para retomar P5) para os aprendizes. Seguem os recortes discursivos:

Eu não sou chegado, eu acho que para a minha vida não vai servir. (EJA) [A10] Eu acho que a língua inglesa não faz diferença na minha vida. (EJA) [A11]

Eu queria espanhol porque eu tenho a minha familia na Argentina. (EJA) [A12]

Eu acho que na escola não é importante, porque aqui na escola não tem nenhum estrangeiro e eu acho que nunca vai ter, ou seja, não terá ninguém com quem os alunos possam utilizar a língua inglesa. (EJA) [A13]

Sobre essas quatro sequências apresentadas, é relevante a informação de que elas partem de aprendizes já (provavelmente) inseridos no mercado de trabalho, pois são alunos da EJA, onde há um número significativo de alunos trabalhadores, ou aqueles que (ainda) não trabalham, já estão mais próximos disso, seja pela proximidade ao colega trabalhador, seja pela vontade de fazer parte desta realidade.

Como havia deixado em aberto esta questão, retomo-a neste momento. Cabe informar que A10, A11, A12 e A13 são alunos de P4, que em seu discurso salientou a importância do saber inglês para o mercado de trabalho, em suas palavras, inglês é muito solicitado em grande parte dos empregos. Volto a questionar: de quais empregos se fala aqui? Uma vez que uma boa parte de seus alunos refutou o saber inglês, como é possível notar especificamente em A10, que diz: eu acho que para a minha vida não vai servir; e em A11, a língua inglesa não faz diferença na minha vida. Nos enunciados desses alunos, não há uma identificação com a língua inglesa, o que dá espaço para imaginar como o discurso do professor desses alunos é descontextualizado. Assim, se esse professor não percebe o que seus próprios alunos imaginam sobre a língua inglesa, como poderá ocorrer, então, um possível deslocamento em sua posição-sujeito para que ele consiga abranger outros saberes, com o intuito de capturar estes sujeitos-aprendizes? A tomada da palavra não é possível sem esse deslocamento.

Voltando aos recortes discursivos, há ainda os dizeres de A12 (Eu queria espanhol) e A13 (não terá ninguém com quem os alunos possam utilizar a língua inglesa) que são voltados para um uso legítimo, objetivo, pragmático, da língua estrangeira, mas que, como esses aprendizes não se veem fazendo parte desta realidade; saber inglês, assim, se torna algo irrelevante, diferentemente do que ocorre com A6, A7 e A8, que se identificam com a língua inglesa ao relacionarem este saber ao que lhes é mais familiar.

Com este agrupamento de enunciados, mesmo ainda ressoando vozes da FD do Repetível Genérico (do interdiscurso), esses alunos se desidentificam desta FD. Não há mais lugar para eles, pois aqui neste espaço a língua inglesa não é importante. E isto não pode ser dito dentro desta FD, deslocam-se, portanto, para a outra FD, que chamarei de FD do Inglês Irrelevante. Desse modo, buscando Pêcheux (1975), o sujeito não fica livre, mas recai sobre outros saberes.

Para finalizar esta passagem, vale dizer que não é interessante que haja aprendizes identificados com a FD do Inglês Irrelevante, pois o seu saber dominante é o de que a língua inglesa não é importante. Neste sentido, é preciso que os alunos e principalmente os professores ocupem uma diferente posição na FD do Repetível Genérico, não reproduzindo fielmente a ideologia dominante, mas sim ocupando outra posição, uma posição-sujeito que abarque outros saberes, não apenas o de que a língua inglesa é (só) importante para o mercado de trabalho. A língua inglesa pode ser 
importante para o mercado de trabalho, mas não é possível que se justifique sua aprendizagem apenas para este fim, que, diga-se de passagem, ilusório e altamente distante, para os aprendizes da escola pública. Para que ocorra a aprendizagem, é necessário que outros saberes, dentro da FD do Repetível Genérico, sejam mobilizados pelos sujeitos que a ela estão filiados.

\section{A (ILUSÃO DA) CONCLUSÃO: UMA POSSÍVEL CAPTURA}

Quando se fala em capturar, é possível que se imagine prender, deter, ou até mesmo aprisionar. No entanto, não é nesta perspectiva que me refiro ao termo capturar, pois um aprisionamento pode significar uma não volta e isto é indesejável. Quando falo em capturar, quero dizer uma busca, neste caso uma busca pelo outro, isto é, uma desestabilização do sujeito. Refiro-me aqui a uma busca pelo fazer sentido, mais especificamente, por uma produção de sentidos em língua estrangeira, uma identificação que é, para Mannoni (1994 apud SERRANI-INFANTE, 1998b, p. 253), "uma captura. Aquele que se identifica talvez creia que está capturando o outro, mas é ele quem é capturado", enfim, um (também) deixar capturar-se.

Para que haja, então, a captura do aprendiz (ou para que ele se deixe capturar) pela/em língua estrangeira, é preciso que ocorra uma identificação com essa língua. Entretanto, essa identificação não é algo que se pode dizer simples, pelo contrário, é uma tarefa que mobiliza uma transformação/modificação no/do sujeito, pois para se identificar com a outra língua, a língua do outro, é requerido do sujeito, como aponta Nardi (2002, p. 112), "um desassossego, [isto é] uma retirada do sujeito de seu espaço (organizado e transparente) para colocá-lo em um desconhecido terreno", a língua estrangeira.

Neste ponto, é interessante voltar às análises dos dizeres de certos sujeitosprofessores (P1, P2, P3, P4 e P5). O que pretendo com isso é enfatizar que o foco dado ao ensino de língua inglesa, na perspectiva desses professores, torna a captura do outro um processo distante, ou seja, não é concebível que se diga ao sujeito-aprendiz que a língua inglesa é somente importante para o mercado de trabalho, parafraseando um silogismo genérico. No caso dos alunos da EJA, como a grande parte já está inserida no mercado de trabalho, mesmo sem saber inglês, o que ocorre é uma não identificação, isto é, a língua inglesa não causa o desassossego. Assim, se o sujeito-professor não der espaço para o diferente, o heterogêneo, não há como capturar o sujeito-aprendiz. Não se pode, portanto, deixar que os alunos passem a ver a língua inglesa (ou outras línguas estrangeiras) como um tanto faz. Desse modo, essa outra língua passa a ser um vazio, um entrever, que preenche uma ou duas horas-aula na grade curricular das escolas públicas.

Finalmente, para que ocorra a captura do sujeito, ou para deixar que ele seja capturado, não é possível que se parafraseie um silogismo genérico. É necessário que se apresente essa língua do outro como um lugar onde se possa dizer talvez aquilo que não se diz na língua materna, a língua como o lugar do diferente, do heterogêneo. 


\section{REFERÊNCIAS}

INDURSKY, F. A fragmentação do sujeito em Análise do Discurso. In: INDURSKY, F.; CAMPOS, M. C. (orgs.). Discurso, memória, identidade. Porto Alegre: Sagra Luzzato, 2000, p.70-81.

NARDI, F. S. Identidade, memória e os modos de subjetivação. In: INDURKY, F.; FERREIRA, M. C. L. (orgs.). Michel Pêcheux e a Análise do Discurso: uma relação de nunca acabar. São Carlos: Claraluz, 2005, p.157-166.

Outros dizeres sobre o ensino de segunda lingua: um lugar para a tomada da palavra no terreno da opacidade e do real. 2002. 156f. Dissertação. [Mestrado em Letras] - Instituto de Letras, UFRGS, Porto Alegre, RS.

ORLANDI, E. P. Análise de Discurso: princípios e procedimentos. $6^{\mathrm{a}}$ ed. Campinas: Pontes, 2005a.

. Análise de Discurso. In: ORLANDI, E. P.; LAGAZZI-RODRIGUES, S.

(orgs.). Discurso e textualidade. Campinas: Pontes, 2006, p.13-31.

As formas do silêncio: no movimento dos sentidos. $6^{\text {a }}$ ed. Campinas: Editora da UNICAMP, 2007.

. Discurso e Texto: formulação e circulação dos sentidos. $2^{\mathrm{a}}$ ed. Campinas: Pontes, 2005b.

Segmentar ou recortar? In: GUIMARÃES, E. (org.). Linguística e questões controversas: série estudos. n. 10. Uberaba: FIUBE, 1984.

PÊCHEUX, M. [1969] Análise Automática do Discurso (AAD-69). In: GADET, F.; HAK, T. (orgs.). Por uma análise automática do discurso: uma introdução à obra de Michel Pêcheux. $3^{\text {a }}$ ed. Campinas: Editora da UNICAMP, 1997, p. 61-161.

. [1975] Semântica e Discurso: uma crítica à afirmação do óbvio. $3^{\text {a }}$ ed. Campinas: Editora da UNICAMP, 1997.

PÊCHEUX, M.; FUCHS, C. [1975] A Propósito da Análise Automática do Discurso: atualização e perspectivas. In: GADET, F.; HAK, T. (orgs.). Por uma Análise Automática do Discurso: uma introdução à obra de Michel Pêcheux. $3^{\mathrm{a}}$ ed. Campinas: Editora da UNICAMP, 1997, p. 163-252.

REVUZ, C. A língua estrangeira entre o desejo de um outro lugar e o risco do exílio. In: SIGNORINI, I. (org.). Língua(gem) e identidade. Campinas: Mercado de Letras; São Paulo: Fapesp, 1998, p. 213-230.

SERRANI-INFANTE, S. Abordagem transdisciplinar da enunciação em segunda língua: a proposta AREDA. In: SIGNORINI, I.; CAVALCANTI, M. C. (orgs.). Linguística Aplicada e transdisciplinaridade. Campinas: Mercado de Letras, 1998a, p.143-67.

Identidade e segundas línguas: as identificações no discurso. In: SIGNORINI,

I. (org.). Língua(gem) e identidade. Campinas: Mercado de Letras; São Paulo: Fapesp, 1998b, p.231-64.

TFOUNI, L. V. Letramento e alfabetização. São Paulo: Cortez, 1995.

TFOUNI, F. E. V.; TFOUNI, L. V. "Entra burro sai ladrão": o imaginário sobre a escola materializado nos genéricos. Linguagem em (Dis)curso - UNISUL, Tubarão/SC, v.7, n. 2. p.293-311, mai/ago. 2007. 